\title{
Pengendalian Perangkat Elektronik Berbasis MIKROKONTROLLER DENGAN ANDROID
}

\author{
CONTROL OF ELECTRONIC DEVICES BASED ON \\ MICROCONTROLLER WITH ANDROID
}

\author{
Fanni Sukma ${ }^{1 a}$, Dwiny Meidelfi ${ }^{2 a, *}$, Ronal Hadi $^{3 a} \&$ Heru Samudera $^{4 b}$ \\ a Politeknik Negeri Padang, Jurusan Teknologi Informasi, Kampus Limau Manis Padang 2516, Indonesia \\ ${ }^{\mathrm{b}}$ Politeknik Negeri Padang, Mahasiswa Alumni Jurusan Teknologi Informasi, Kampus Limau Manis \\ Padang 2516, Indonesia \\ Telp. 0751-72590 Fax. 0751-72576
}

Email : fannisukma@pnp.ac.id,dwinymeidelfi@pnp.ac.id,ronalhadi@pnp.ac.id, heru.samudera@gmail.com

\begin{abstract}
AbStrak
The very rapid development of technology and the high level of human innovation have made the emergence of increasingly sophisticated technological products, one of which is the MCU node, a microcontroller system that has been integrated with various electronic modules and by using the $C++$ programming language, the automatic smarthome control system, is one of the technological advances in the field of mechanics and electronics, both digital and analog, by integrating a smartphone as a remote to turn on and turn off certain electrical equipment using the mcu node as the main control and a link between smartphones. Remote application smarthome as a media user interface for giving commands via the smartphone which will be executed by the mcu node and then the relay which will execute the electrical equipment installed at home.
\end{abstract}

Keywords : MCU Node, Smarthome, Smartphone, Application

\section{Pendahuluan}

Seiring dengan perpindahan dan pergerakan manusia yang semakin cepat dan luas, maka kebutuhan akan sistem pengendalian jarak jauh juga semakin meningkat. Aktivitas hampir setiap individu di kota besar sangatlah padat dengan berbagai macam pekerjaannya. Hal ini tentunya akan memakan waktu yang cukup lama dari pagi hingga malam hari. Akibatnya banyak kegiatan di rumah tangga yang tertunda dan mungkin saja terlupakan, seperti menghidupkan atau mematikan perangkat elektronik di setiap ruangan.

Perkembangan teknologi saat ini mendorong manusia untuk terus berpikir kreatif, tidak hanya menggali penemuan-penemuan baru, tetapi juga memaksimalkan kinerja teknologi yang ada untuk meringankan pekerjaan manusia dalam kehidupan sehari-hari seperti pengendalian perangkat elektronik. Oleh karena itu, apabila seluruh perangkat elektronik dalam suatu rumah dikendalikan tanpa harus menyalakan saklar atau tombol on/off di dalam rumah maka peran mikrokontroler, smartphone android, serta fasilitas Node Mcu sangat penting untuk memberi kenyamanan dan kemudahan khususnya untuk para penyandang cacat fisik atau orang yang selalu bepergian jauh[1].

Berdasarkan permasalahan tersebut, dilakukan kegiatan pembangunan prototype aplikasi sistem pengendalian perangkat elektronik yang dibangun di platform Android sebagai solusi alternatif baru untuk pengendalian jarak jauh. Aplikasi yang dibangun pada platform Android ini memiliki tampilan antarmuka (user interface) yang menarik dan mudah dipahami. Selain itu sistem pengendalian yang dibangun memanfaatkan jaringan internet untuk pengiriman instruksi pengendaliannya ke Node Mcu. Pemanfaatan smartphone Android sebagai alat komunikasi dan telepon cerdas telah banyak mengalami perkembangan saat ini, seperti sebagai alat pengendalian perangkat elektronik di rumah yang dipadukan dengan komponen mikrokontroler dan memanfaatkan fasilitas Node Mcu yang ada pada smartphone Android. Dari kemudahan dan menjamurnya smartphone Android dikalangan masyarakat, maka penulis mengambil judul penulisan smart home berbasis mikrokontroler arduino menggunakan smartphone android. 
Untuk mewujudkan penelitian ini, dilakukan pencarian berbagai referensi tentang teknologi sistem pengendalian pada perangkat elektronik, baik menggunakan smartphone atau perantara elektronika, kemudian mencari kelebihan dan kekurangan masing-masing sistem.

\section{A. Smarthome}

Smarthome atau Rumah Pintar adalah sebuah sistem berbantuan komputer yang akan memberikan segala kenyamanan, keselamatan, keamanan dan penghematan energi, yang berlangsung secara otomatis dan terprogram melalui komputer, pada gedung atau rumah tinggal. Dapat digunakan untuk menggendalikan hampir semua perlengkapan dan peralatan di rumah, mulai dari pengaturan tata lampu hingga ke berbagai alat-alat rumah tangga, yang perintahnya dapat dilakukan dengan menggunakan suara, sinar inframerah, atau melalui kendali jarak jauh (remote)[2].

\section{B. Sistem Kendali Otomatis}

Sistem kendali otomatis merupakan suatu teknologi yang menghubungkan sistem mekanik, elektronika dan kelistrikan di dalam sistem informasi yang berfungsi sebagai alat kontrol atau pengendal. Produk elektronika yang menggunakan sistem kendali otomatis merupakan sebuah alat yang dapat bekerja sesuai dengan kehendak penggunanya.

Dalam menggerakkan proses dan mengoperasikan program serta sistem kendali. Sistem pengendali menggunakan sensor yang memberikan suatu informasi sebagai input ke pemberi perintah yakni otak, agar memberikan tindakan yaitu output. Proses pembaca sensor ini, merupakan elemen dari sistem pengendali[3].

\section{Android}

Android adalah sistem operasi yang berbasis Linux untuk telepon seluler seperti telepon pintar dan komputer tablet. Android menyediakan platform terbuka bagi para pengembang untuk menciptakan aplikasi mereka sendiri untuk digunakan oleh bermacam peranti bergerak[6].

\section{Mikrokontroler}

Mikrokontroller adalah suatu IC yang didesain atau dibentuk dengan kepadatan yang sangat tinggi, dimana semua bagian yang diperlukan suatu kontroler sudah dikemas dalam satu keeping. Biasanya terdiri dari CPU, RAM, EEPROM/EPROM/PROM/ROM, I/O, Serial \& Parallel, Timer, Interupt Controller dan berfungsi sebagai pengontrol rangkaian elektronik serta umunya dapat menyimpan program didalamnya[4].

\section{E. Node MCU}

NodeMCU adalah sebuah platform IoT yang bersifat open source. Terdiri dari perangkat keras berupa System On Chip ESP8266 dari ESP8266 buatan Espressif System, juga firmware yang digunakan, yang menggunakan bahasa pemrograman scripting Lua. Istilah NodeMCU secara default sebenarnya mengacu pada firmware yang digunakan daripada perangkat keras development kit[5].

NodeMCU bisa dianalogikan sebagai board arduino-nya ESP8266. Dalam seri tutorial ESP8266 embeddednesia pernah membahas bagaimana memprogram ESP8266 sedikit merepotkan karena diperlukan beberapa teknik wiring serta tambahan modul USB to serial untuk mengunduh program. Namun NodeMCU telah me-package ESP8266 ke dalam sebuah board yang kompak dengan berbagai fitur layaknya mikrokontroler + kapabilitas akses terhadap Wifi juga chip komunikasi USB to serial. Sehingga untuk memprogramnya hanya diperlukan ekstensi kabel data USB persis yang digunakan sebagai kabel data dan kabel charging smartphone Android.

\section{F. Telegram}

Telegram adalah aplikasi pesan instan berbasis cloud yang fokus pada kecepatan dan keamanan. Telegram dirancang untuk memudahkan pengguna saling berkirim pesan teks, audio, video, gambar dan stiker dengan aman. Secara default, seluruh konten yang ditransfer akan dienkripsi berstandar internasional. Dengan demikian, pesan yang terkirim sepenuhnya aman dari pihak ketiga, bahkan dari Telegram sekalipun. Bukan hanya teks, gambar dan video, Telegram juga bisa jadi sarana untuk mengirimkan dokumen, musik, berkas zip, lokasi real-time dan kontak yang tersimpan di perangkat ke orang lain. Asal, orang yang dituju juga mempunyai aplikasi dengan akun Telegram terdaftar di perangkatnya[7].

Karena berbasis cloud, maka penggunanya dapat mengakses pesan dari perangkat yang berbeda secara bersamaan dan membagikan jumlah berkas yang tak terbatas hingga 1,5GB. Berkas ini dapat diatur untuk disimpan di dalam perangkat atau hanya di cloud.

\section{Metodologi}

Metodologi pada penelitian ini dimulai dari pengumpulan data, analisis sistem, desain sistem, dan implementasi. Keseluruhan metode ini ditampilkan pada Gambar 1. 


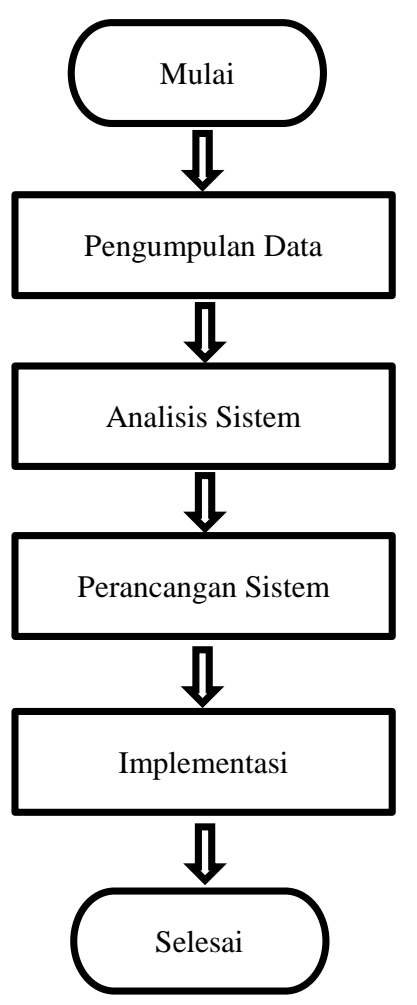

Gambar 1. Diagram Alir Pembuatan Sistem

\section{Pengumpulan Data}

Metode pengumpulan data yang dilakukan dalam penelitian ini adalah :

a. Wawancara : Melakukan wawancara mengenai sistem kendali pada perangkat elektronik bersama narasumber yang merupakan salah satu ahli dalam bidang mikrokontroler.

b. Observasi : Mengunjungi beberapa situs mengenai sistem kendali pada perangkat elektronik terhadap teknologi yang digunakan.

\section{Analisis Sistem}

Pada penelitian ini dilakukan analisis terhadap sistem pengendalian perangkat elektronik rumah yang telah ada, mencari tahu mengenai teknologi yang digunakan, serta kelebihan dan kelemahan masing-masing dari sistem.

\section{Perancangan Sistem}

Melakukan perancangan sistem untuk pengendalian perangkat elektronik rumah, mulai dari database, nodemcu, dan aplikasi android.

\section{Implementasi}

Implementasi merupakan kegiatan akhir dari proses penerapan sistem baru, dimana tahap ini merupakan tahap meletakkan sistem supaya siap untuk dioprasikan dengan memanfaatkan Node Mcu yang ada pada smartphone.

\section{ANalisis Dan Perancangan SISTEM}

\section{A. Analisis Sistem}

Untuk mengevaluasi dan mengidentifikasi suatu permasalahan maka dilakukanlah analisa sistem yang diharapkan nantinya dapat diusulkan perbaikan. Perancangan sistem kendali otomatis smarthome berbasis android menggunakan teknologi wifi (Node Mcu) adalah sistem yang digunakan untuk mengendalikan listrik pada beberapa peralatan listrik rumah, sistem ini akan menggabungkan rangkaian listrik pada peralatan listrik rumah menjadi satu kesatuan dalam fungsi pengontrolannya. Sistem ini digabungkan dengan sebuah mikrokontroler arduino yang di program dengan bahasa pemrograman $\mathrm{C}$, dengan pembangunan sistem ini pengguna tidak harus mengontrol perangkat elektronik dengan datang ke tempat pusat pengontrolan perangkat elektronik, pengguna dapat mengontrol, menyalakan dan mematikan peralatan listrik dengan smartphone sesuai dengan kebutuhan. Sistem ini dikendalikan dengan sebuah aplikasi telegram yang terkoneksi wifi pada perangkat android untuk setiap pengaturan dan pengontrolan perangkat elekronik, sehingga sistem dapat dikendalikan dengan jarak jauh.

Dalam pembangunan sistem ini ada beberapa ketentuan yang harus dipenuhi, baik secara penggunaan maupun secara teknis. Penggunaan aplikasi Remote smarthome ini tidak semua orang yang memiliki, dapat menggunakannya. Dalam pelaksanaannya sistem ini akan melakukan perintah sesuai dengan perintah penggunanya. Berikut analisis sistem yang ada pada perancangan sistem kendali otomatis smarthome berbasis android menggunakan teknologi wifi (Node $\mathrm{Mcu})$ :

1. Menyalakan dan mematikan lampu dengan mengetik perintah pada perangkat android di aplikasi telegram.

2. Sistem smarthome dikontrol pada aplikasi berbasis android yang terkoneksi dengan wifi setempat.

3. Server hanya menampilkan data history saja yang dapat dilihat oleh semua pengguna dengan mengakses link khusus.

\section{B. Rancangan Sistem}

Perancangan sistem merupakan suatu kegiatan pengembangan prosedur dan proses yang sedang berjalan untuk menghasilkan suatu sistem yang baru, atau memperbaharui sistem yang ada untuk meningkatkan efektifitas kerja agar dapat memenuhi hasil yang digunakan dengan tujuan 
memanfaatkan teknologi dan fasilitas yang tersedia. Pada bagian ini akan memberikan usulan yang merupakan sistem informasi secara komputerisasi yang diharapkan akan membantu mempermudah aktivitas sehari hari.

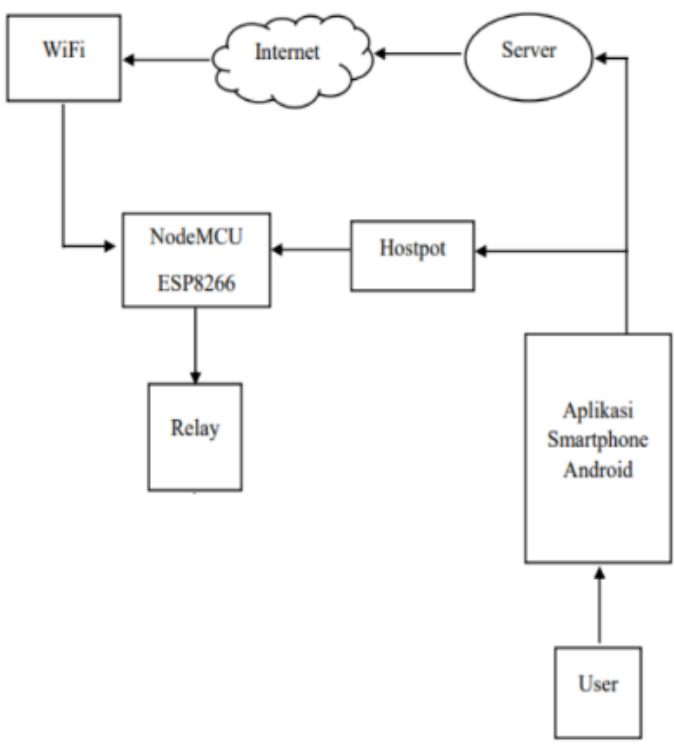

Gambar 2. Diagram Sistem

Sesuai dengan diagram pada gambar 2, aplikasi smartphone android yang digunakan sebagai input terdapat link untuk mengontrol pengkat elekronik. Wifi Nodemcu yang terhubung dengan internet akan menerima data request dari smartphone android ke server. Data request yang dikirim ke server akan disimpan di database. Data request tersebut memiliki 2 keadaan yaitu perangkat mati dan perangkat menyala. Selanjutnya data dari server akan diteruskan ke Nodemcu dan diolah di Nodemcu kemudian dikirim ke relay lalu relay akan memberikan atau memutuskan arus. Jika relay memberikan arus maka perangkat akan menyala, jika tidak maka sebaliknya.

C. Rancangan Sistem Hardware dan Software Sistem ini terdiri dari 2 bagian rancangan utama yaitu :

1. Perancangan sistem perangkat keras

Komponen fisik yang digunakan untuk membentuk rangkaian elektronika sistem dapat terlihat pada gambar 3. Perangkat keras dan elektronika yang digunakan membuat sistem terdiri dari beberapa bagian utama yaitu sirkuit utama (main board), sensor dan konektifitas. Setiap komponen ini membutuhkan antar muka yang merupakan jalur komunikasi antar komponen. Perancangan antarmuka harus dilakukan sebaik mungkin dan diperhatikan apa yang menjadi kekurangan dan kelebihannya. Kemudian perancangan perangkat keras agar dapat diletakan di tempat yang strategis.

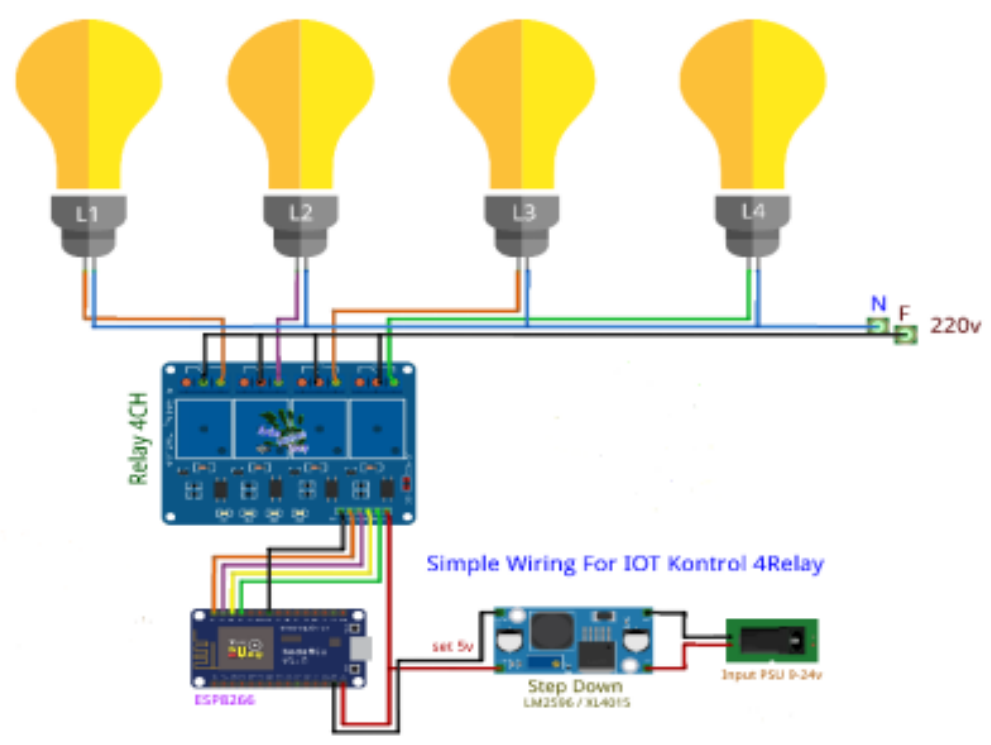

Gambar 3. Diagram Sistem 


\section{Perancangan Sistem Perangkat Lunak}

Tahap selanjutnya adalah merancang sistem perangkat lunak untuk telepon pintar yang berbasis android, dalam tahap ini penulis membangun sebuah aplikasi menggunakan telegram, telegram ini merupakan sebuah aplikasi yang menyediakan system chat, dan mendapatkan api untuk menghubungkannya ke node mcu, sedangkan pembuatan kontaknya menggunakan bot father.

Rancangan perangkat lunak sendiri meliputi :

a. Program mikrokontroler arduino dibuat dengan bahasa pemrograman C Arduino IDE.

b. Aplikasi android menggunakan jasa telegram.

c. Untuk pembuatan server history menggunakan jasa aws educate.

\section{Rancangan Basis Data}

Pada perancangan basis data dibuat sebuah database yang terdiri dari satu tabel yaitu tabel server. Tabel server berfungsi sebagai table yang nantinya untuk melihat history dari perintah yang di akses dari android. Data akan update pada database jika aksesan nya benar. Tabel ini memiliki 5 field, untuk lebih jelasnya dapat di lihat pada Tabel 1.

Tabel 1. Struktur Data Base

\begin{tabular}{ccc}
\hline No & Field & Tipe Data \\
\hline 1 & Id_server & Int(10) auto increment \\
2 & Tipe_relay & Varchar(20) \\
3 & Status & tinyint(20) \\
4 & Deskripsi & Varchar(20) \\
5 & Waktu & Datetime \\
\hline
\end{tabular}

\section{E. Rancangan Antarmuka}

Perancangan antarmuka atau interface dilakukan untuk menentukan bentuk aplikasi secara fisik. Pada sistem ini, desain tampilan aplikasi android memanfaatkan telegram dengan membuat sebuah bot dan mendapatkan API di telegram.

\section{IMLEMENTASI DAN HASIL Pengujian}

\section{A. Implementasi User Interface Server Aws}

Implementasi pada server aws ini dimana dilakukan dengan menghosting data table yang dikirim dari node mcu berupa kata input dan outpunya, seperti yang ada pada Tabel 1 tentang strutur database. Berikut langkahnya :

1. Pada Gambar 4 merupakan tampilan awal aws educate, memilih go to classroom dan memilih aws console dan menu instances.

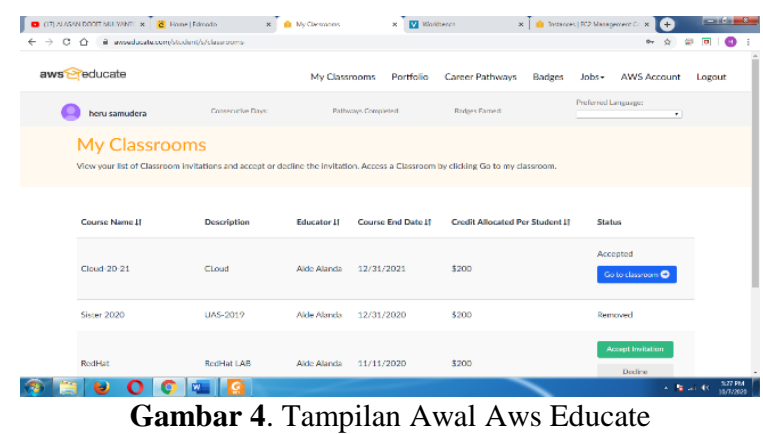

2. Kemudian pada gambar 5 dapat dipiilih launch instances dan select ubuntu server.

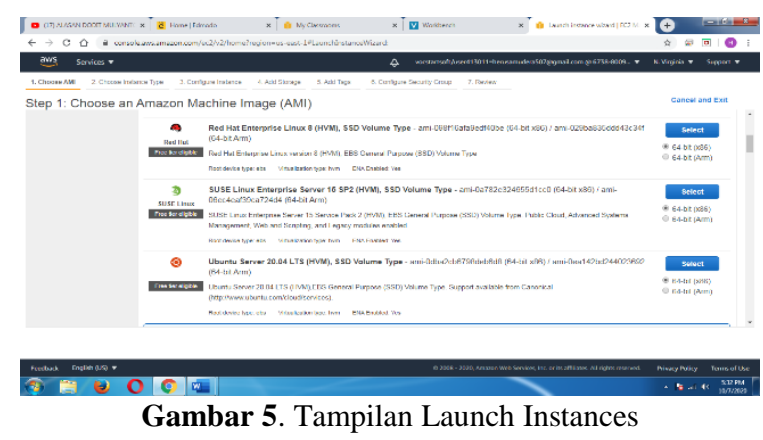

3. Pada tahap ini sesuai dengan gambar 6 dilakukan add rule dan add all tcp.

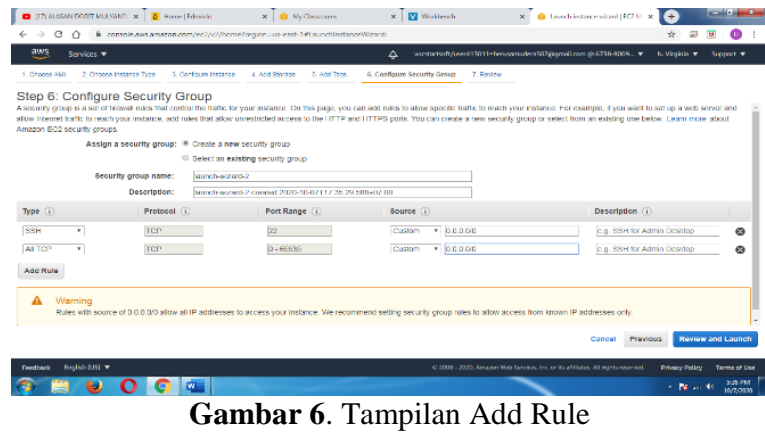

4. Selanjutnya, melakukan pemilihan key sesuai dengan gambar 7 .

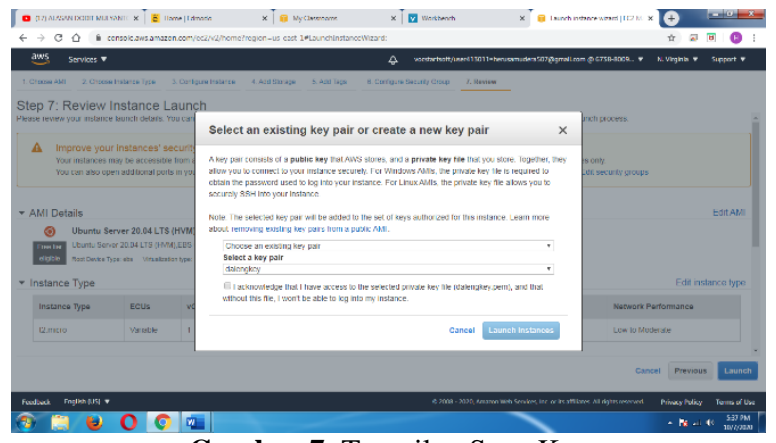

Gambar 7. Tampilan Save Key

5. Kemudian instances 1 akan terbuat secara otomatis sesuai dengan yang terlihat pada gambar 8 . 


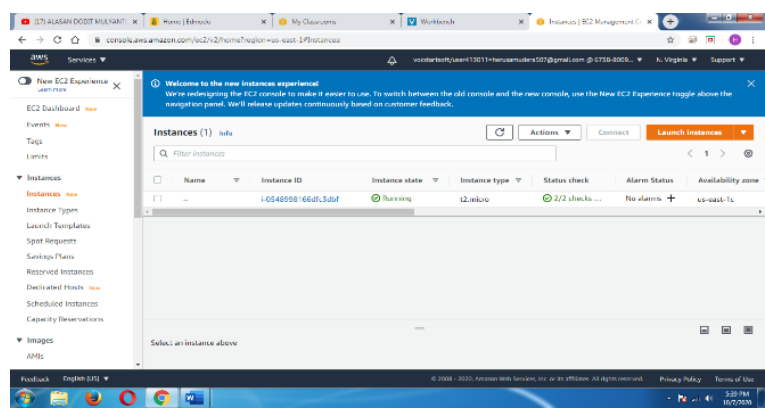

Gambar 8. Tampilan Instances 1

6. Selanjutnya membuka putty gen untuk melakukan generate key. Gambar 9 merupakan tampilan awal putty gen.

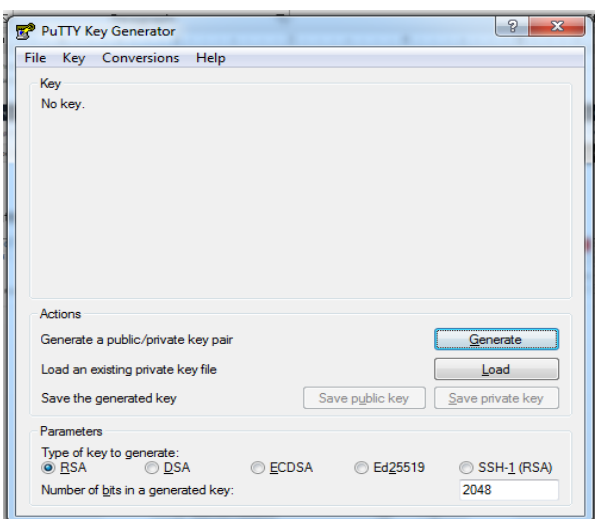

Gambar 9.Ttampilan Putty Gen

7. Berikutnya membuka putty untuk melakukan remote server, dengan memasukan hostname pada instances 1 sesuai dengan gambar 10 .

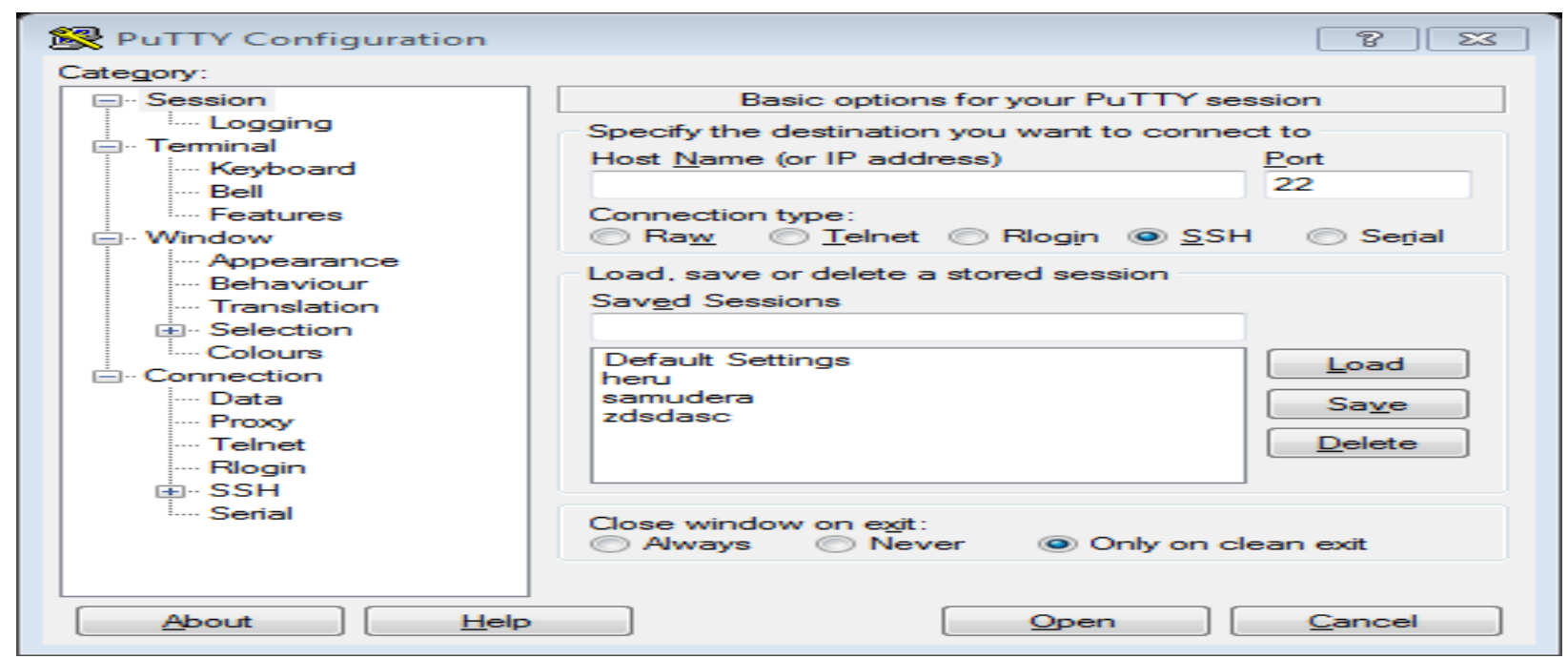

Gambar 10. Tampilan Putty Configuration

8. Berikutnya memilih perintah seperti Gambar 11 untuk mendapatkan get aapanel.

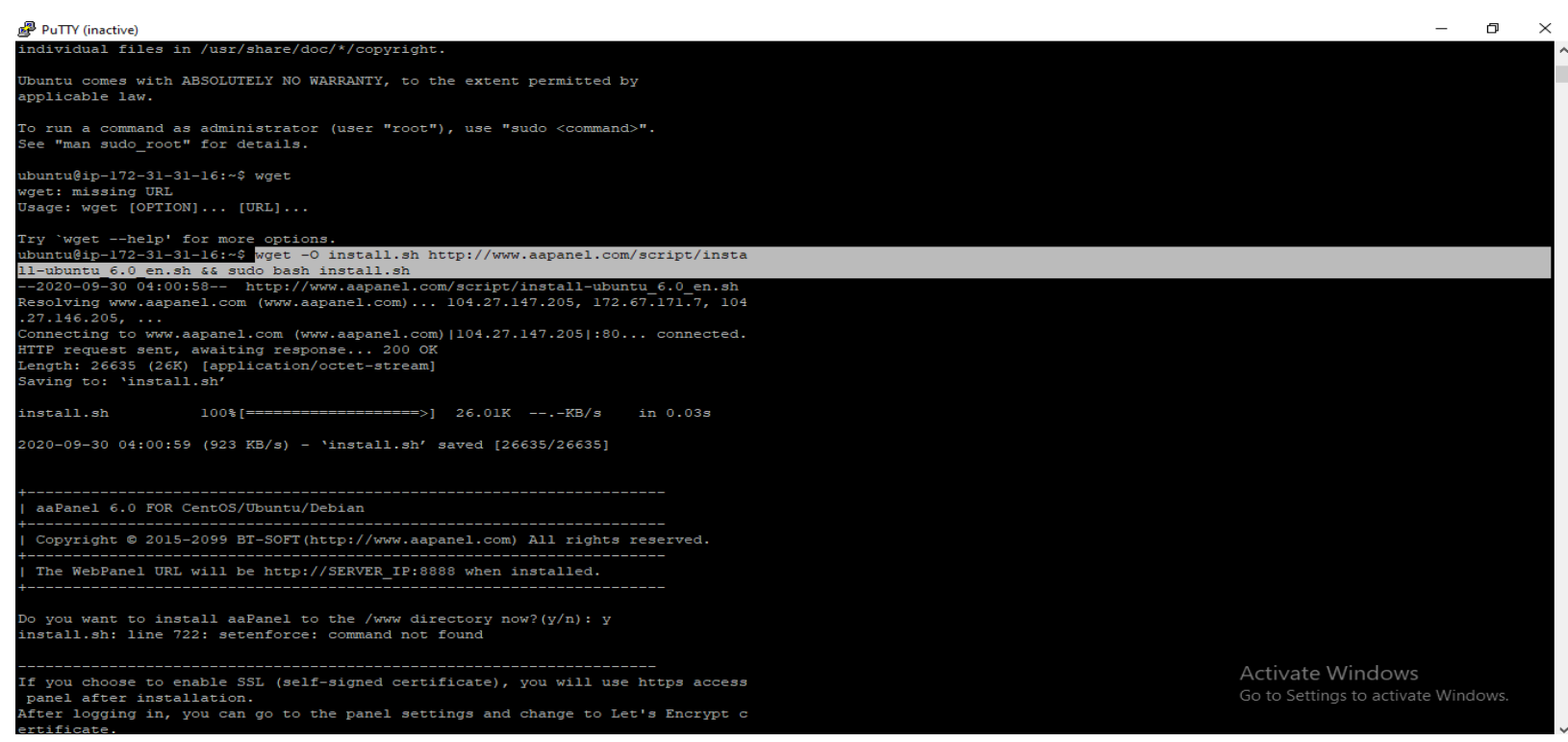

Gambar 11. Putty Get Aapanel 
9. Pada aapanel akan mendapatkan link address dan user untuk access ke aapanel seperti tampilan pada gambar 12.

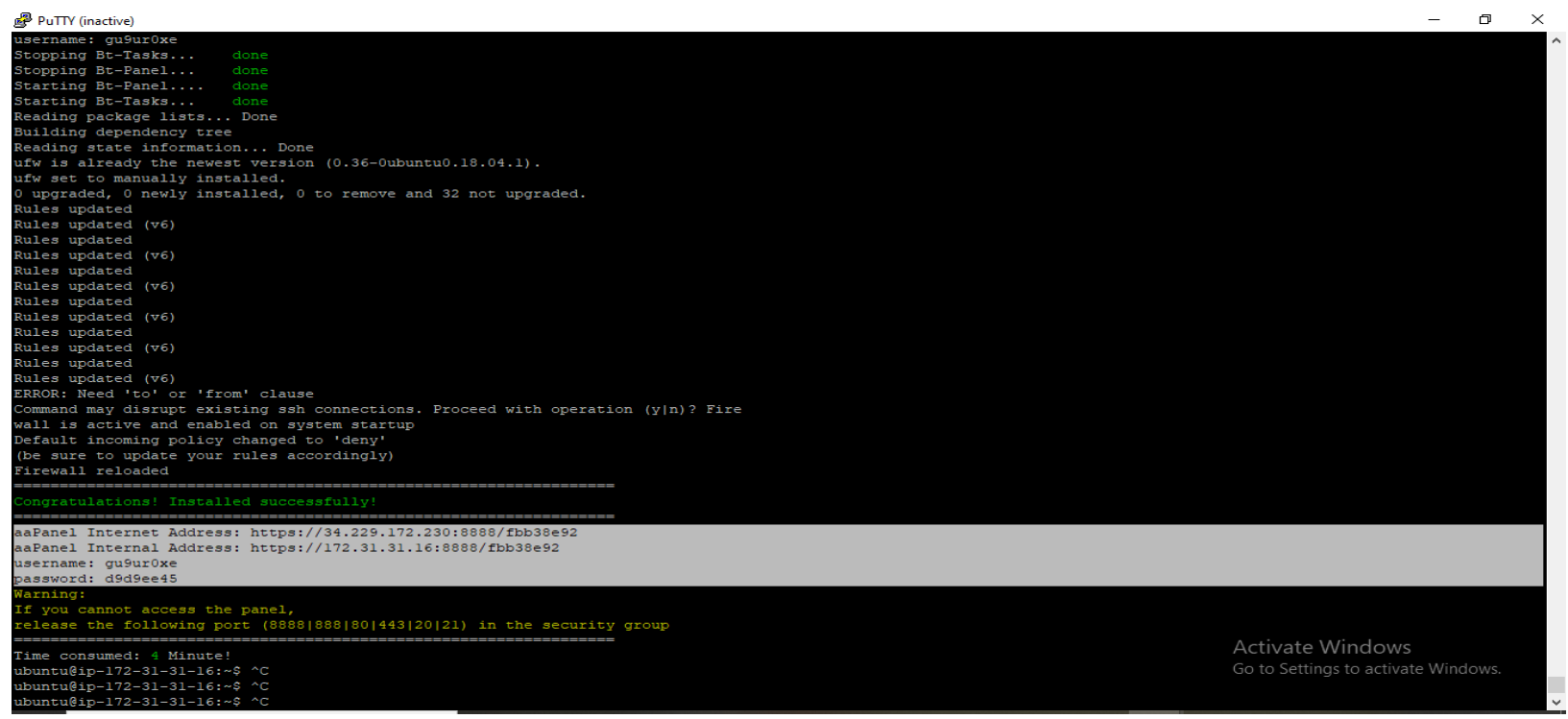

Gambar 12. Tampilan Setelah Get Aapanel

10. Kemudian instances 1 akan terbuat secara otomatis sesuai dengan yang terlihat pada gambar 8.

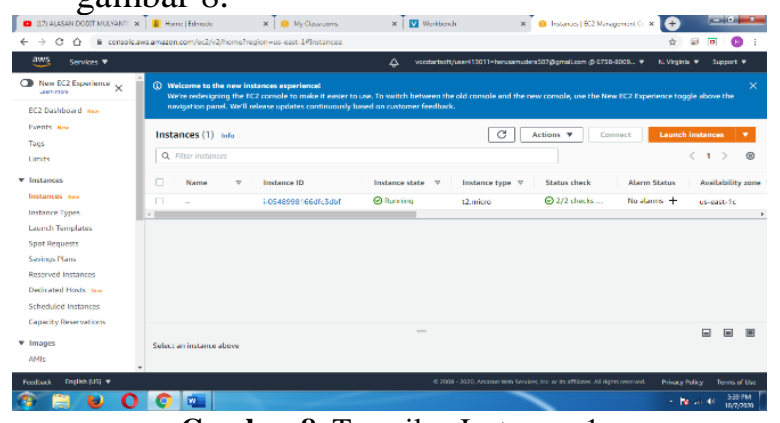

Gambar 8. Tampilan Instances 1

11. Selanjutnya membuka putty gen untuk melakukan generate key. Gambar 9 merupakan tampilan awal putty gen.

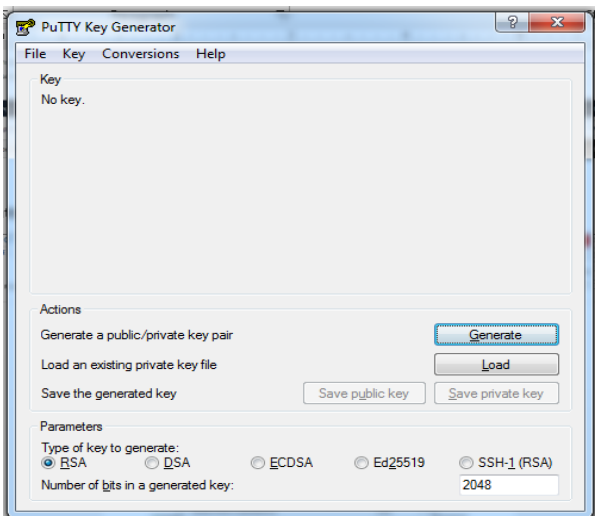

Gambar 9.Ttampilan Putty Gen

12. Berikutnya membuka putty untuk melakukan remote server, dengan memasukan hostname pada instances 1 sesuai dengan gambar 10 .

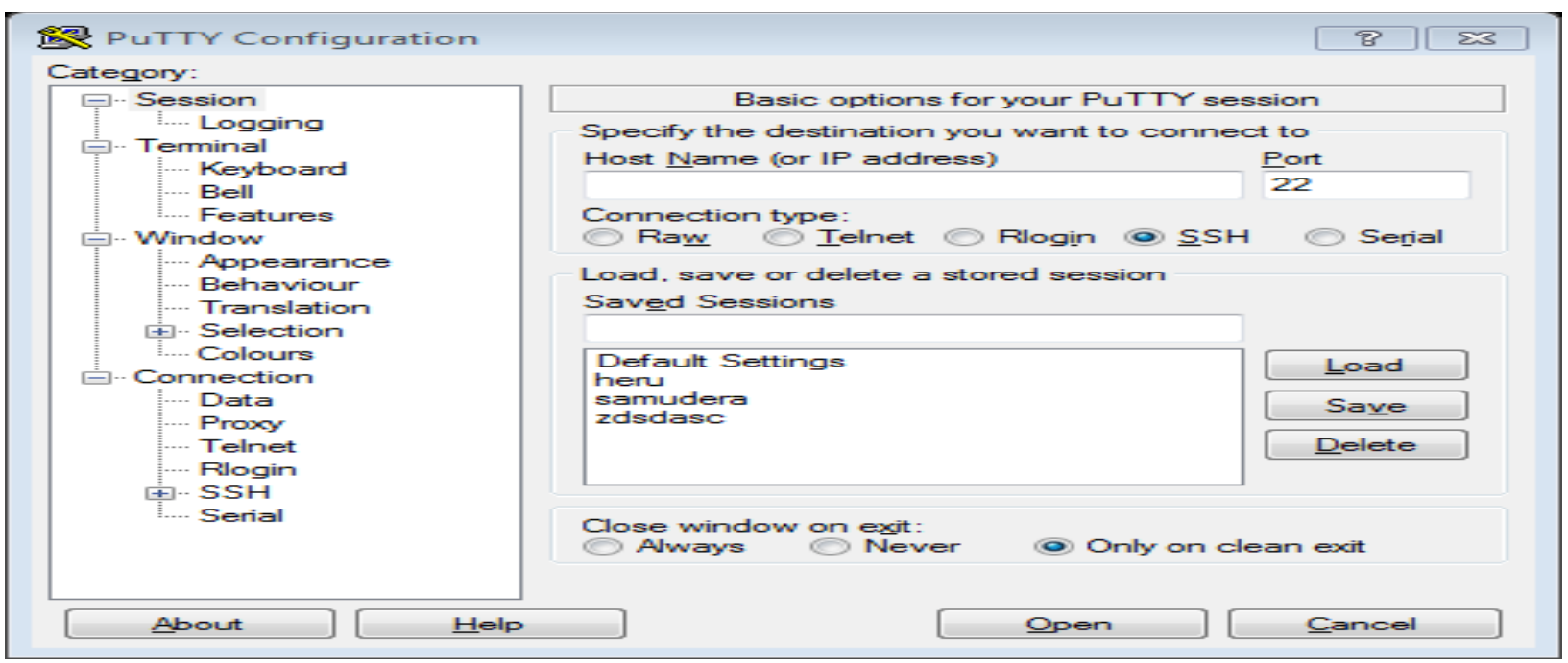

Gambar 10. Tampilan Putty Configuration 
13. Berikutnya memilih perintah seperti Gambar 11 untuk mendapatkan get aapanel.

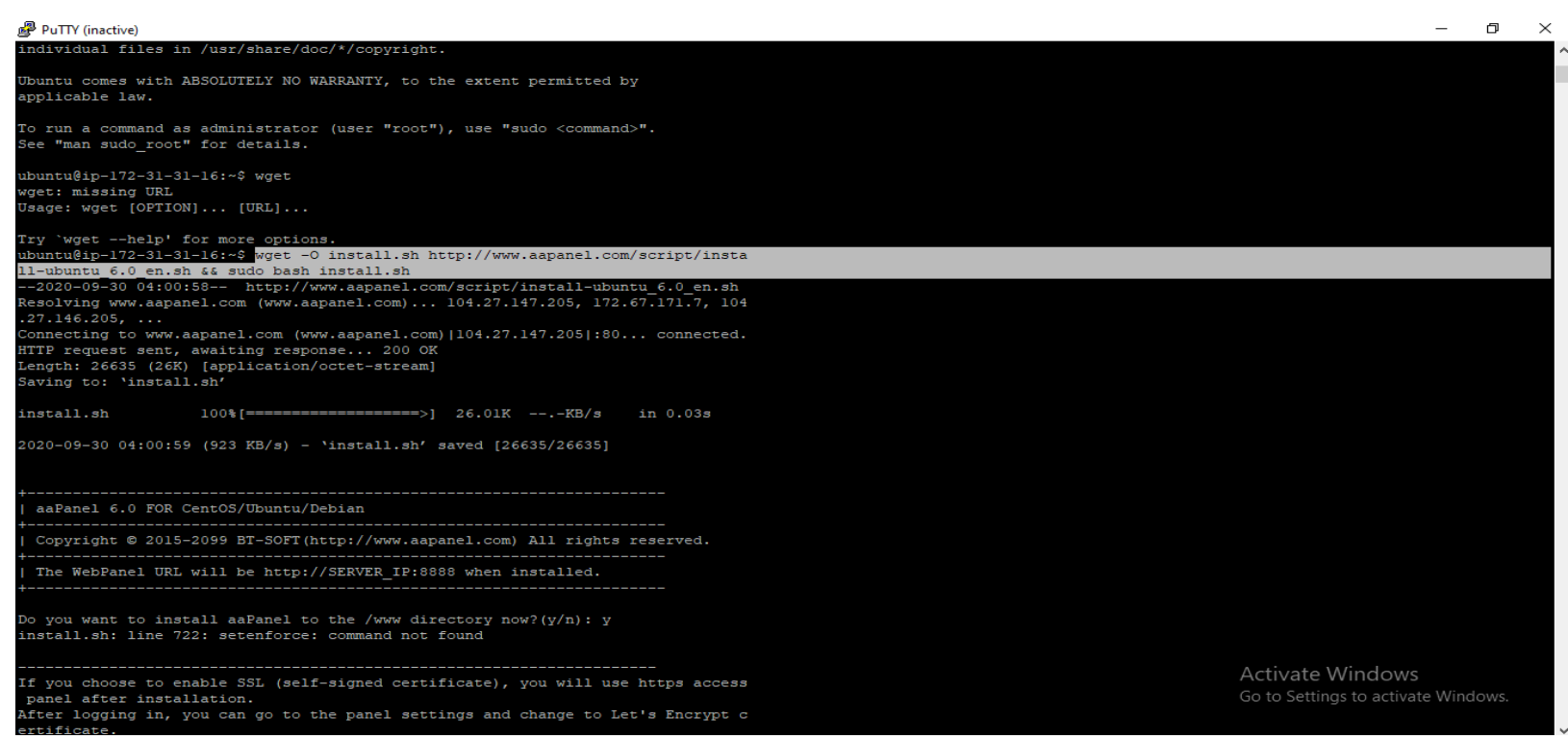

Gambar 11. Putty Get Aapanel

14. Pada aapanel akan mendapatkan link address dan user untuk access ke aapanel seperti tampilan pada gambar 12 .

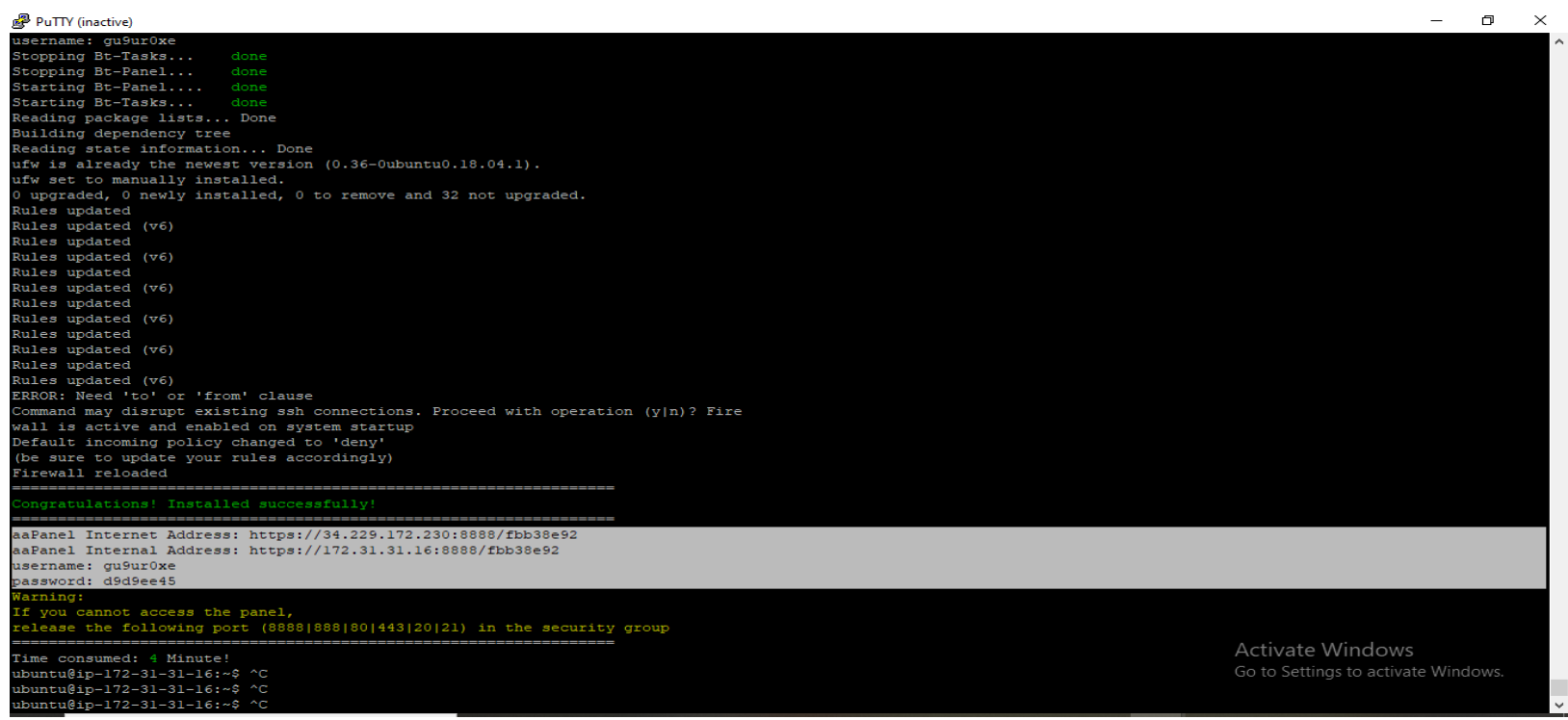

Gambar 12. Tampilan Setelah Get Aapanel

15. Selanjutnya membuka link address tersebut di browser. Gambar 13 merupakan tampilan awal aapanel.

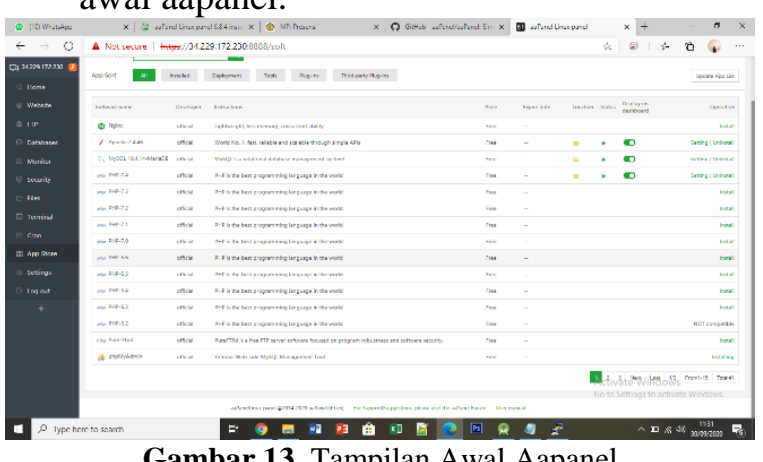

Gambar 13. Tampilan Awal Aapanel
16. Pada gambar 14 dilakukan penmbuatan database baru.

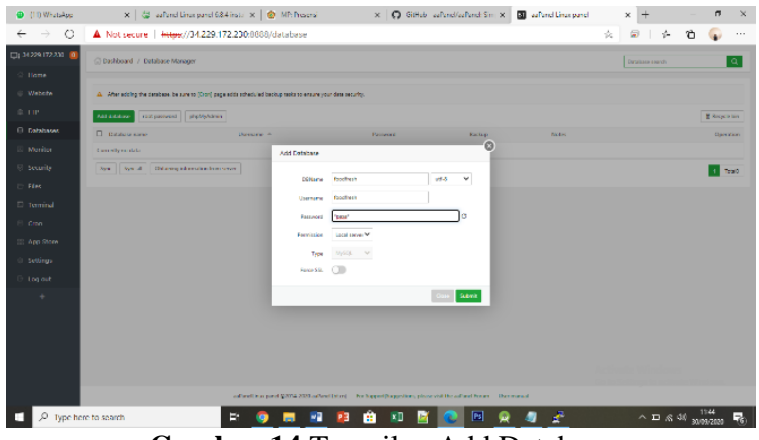

Gambar 14.Tampilan Add Database 


\section{B. Implementasi User Interface Android (Telegram)}

Setelah rancangan system telegram, aplikasi dapat di access di smartphone android. Berikut hasil implementasi dari aplikasi tersebut :

1. Pada aplikasi Telegram, dilakukan pencarian bot yang telah di buat seperti pada gambar 18 .

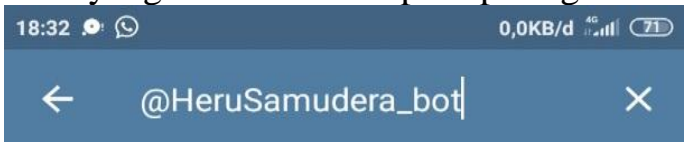

N NodeMcu

@HeruSamudera_bot

Gambar 18. Cari Name Bot

2. Kemudian memulai dengan memilih start, sehingga terlihat halaman seperti pada gambar 19.

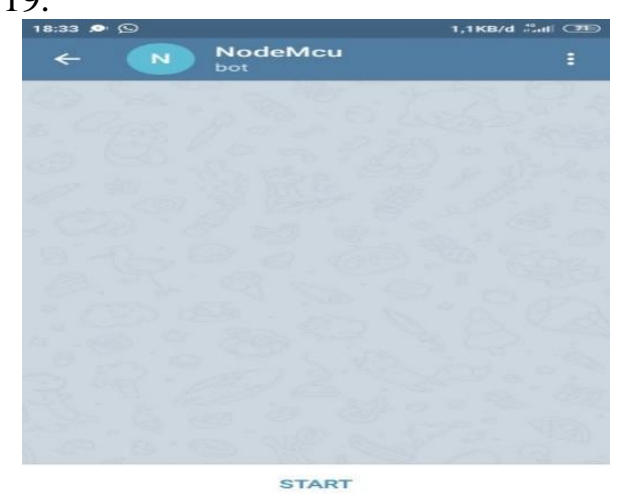

Gambar 19. Tampilan Awal Bot

3. Selanjutnya akan muncul deskripsi dan link aksesnya seperti tampilan pada gambar 20 .

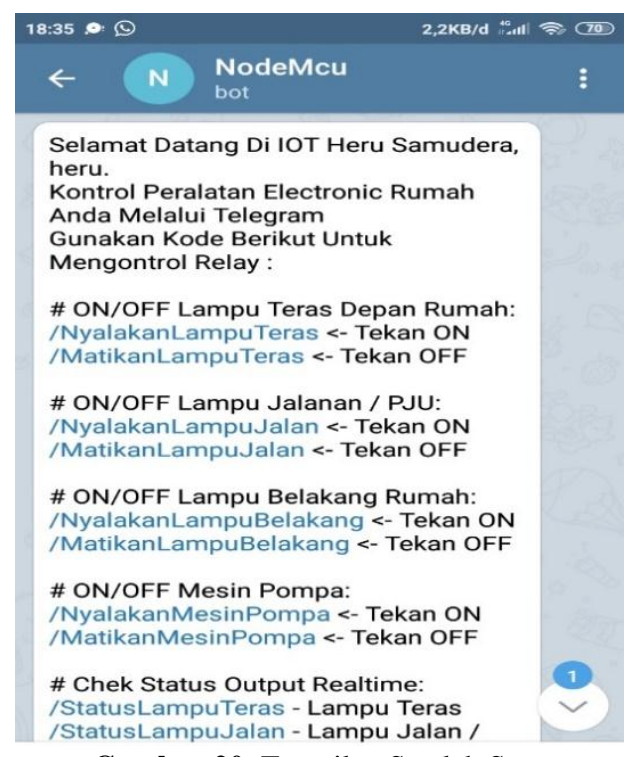

Gambar 20. Tampilan Setelah Start

\section{Implementasi Instalasi Hardware}

Semua perangkat yang tersedia dihubungkan menjadi satu sistem, berikut tahapannya.

1. Menghubungkan node mcu dengan relay dengan kabel jumper seperti yang terlihat pada gambar 21.

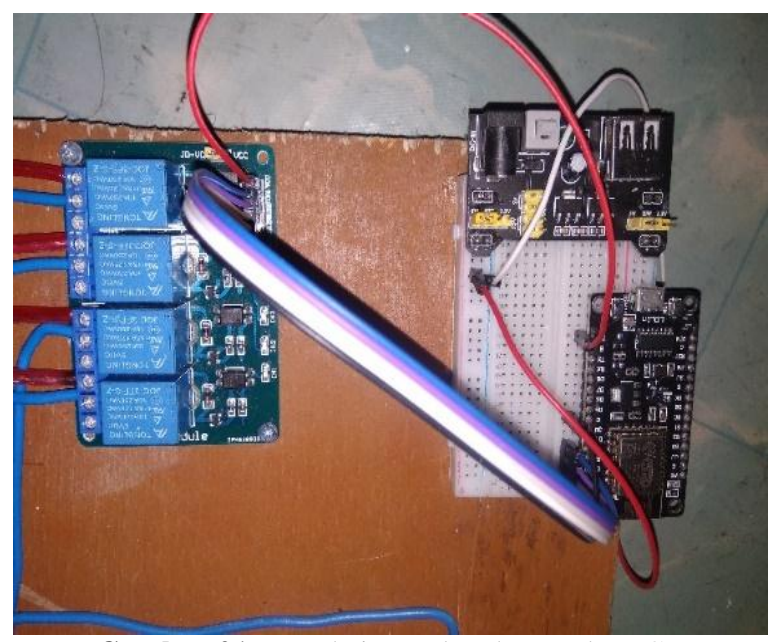

Gambar 21. Rangkaian Relay dan Node MCU

Pada tabel 2 merupakan penghubung antar node mcu dengan relay :

Tabel 2. Penghubung NodeMCU Relay

\begin{tabular}{cc}
\hline VCC & 3 VOL \\
\hline GND & GND \\
IN 1 & D 0 \\
IN 2 & D 1 \\
IN 3 & D 2 \\
IN 4 & D 3 \\
\hline
\end{tabular}

2. Menghubungkan relay dengan lampu seperti pada gambar 22

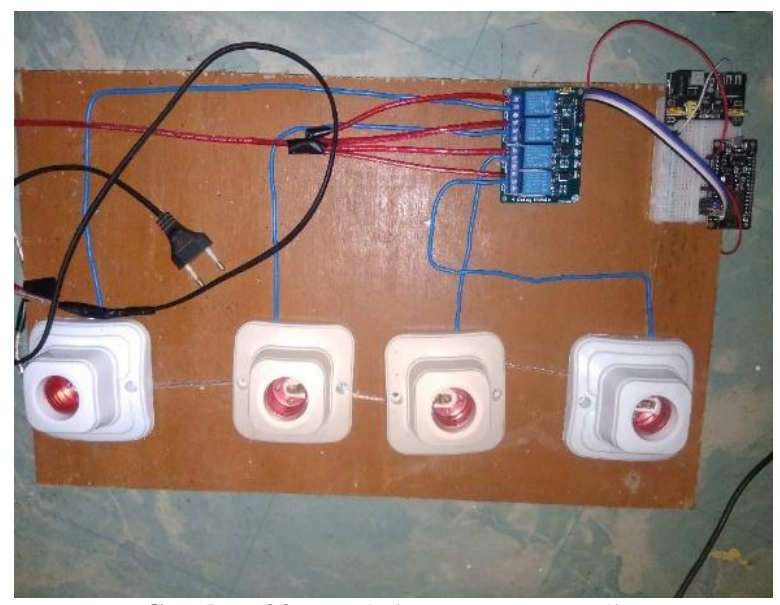

Gambar 22. rangkaian system complite

\section{Hasil Pengujian}

Hasil dari pengujian sistem ini akan ditampilkan dalam beberapa tahap berikut : 


\section{Hasil Pengujian Sistem}

Hal yang di lakukan pertama yaitu menghubungkan system/node mcu ke wifi, user dan password wifi harus sama dengan program Arduino. Berikut hasilnya :

a. Uji lampu 1

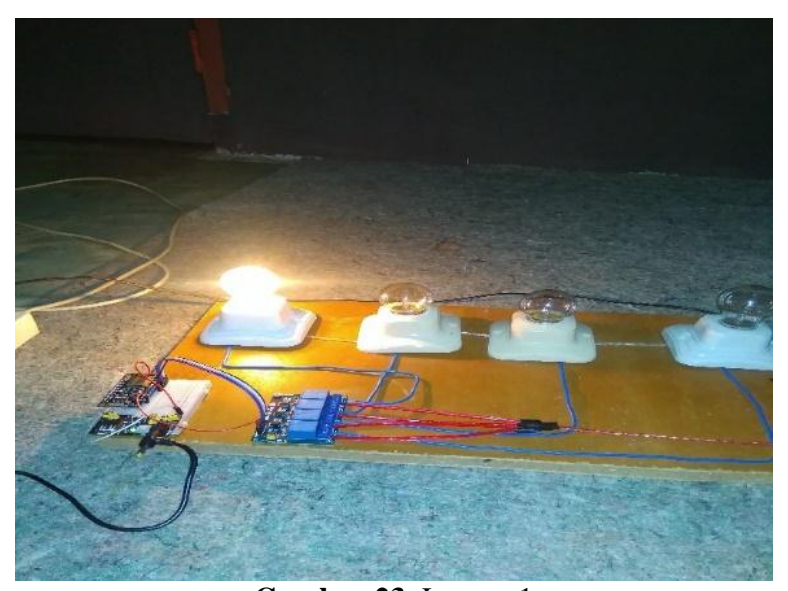

Gambar 23. Lampu 1

b. Uji lampu 2

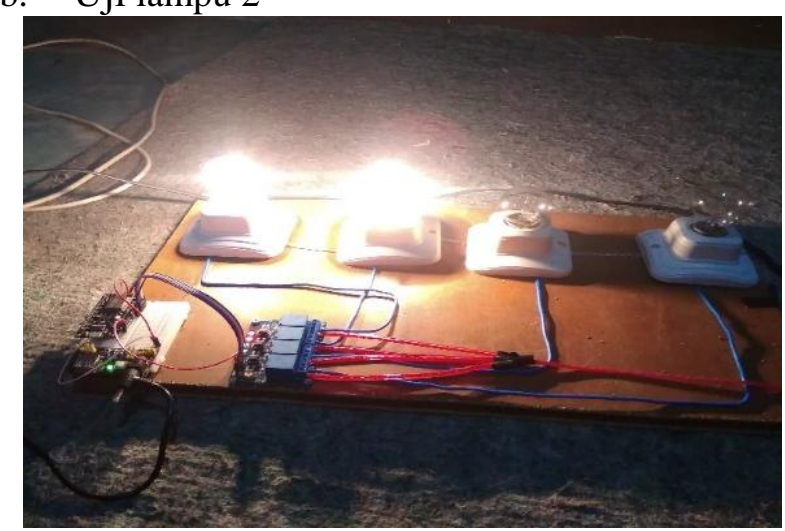

Gambar 23. Lampu 2 c. Uji lampu 3

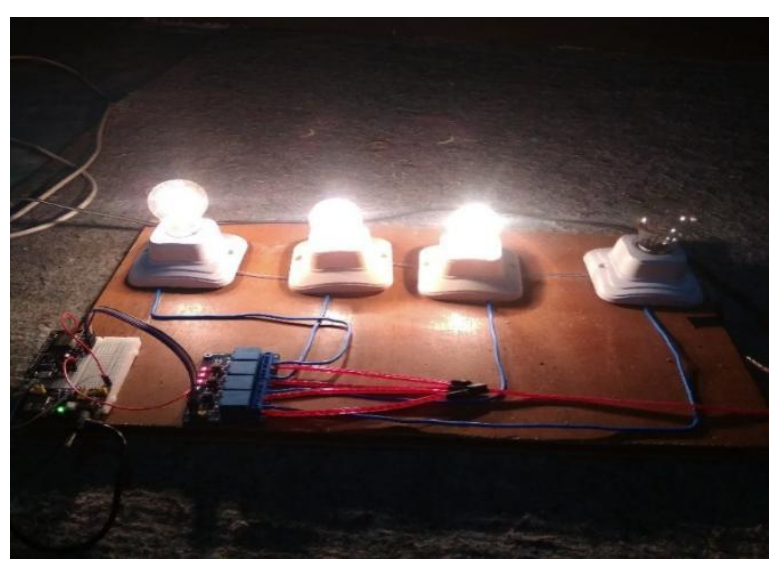

Gambar 25. Lampu 3

d. Uji lampu 4

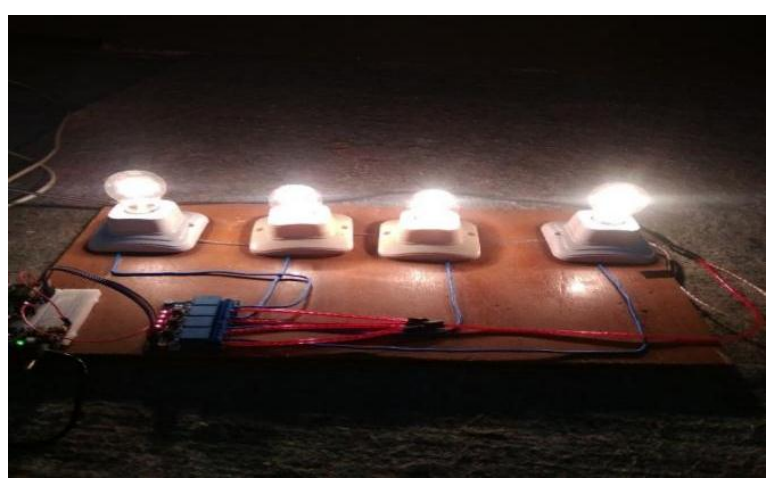

Gambar 26. Lampu 4

\section{Hasil Pengujian Server}

Tabel 3. Tabel Server History

\begin{tabular}{cccclc}
\hline No & $\begin{array}{c}\text { Id } \\
\text { Server }\end{array}$ & Tipe Relay & Status & \multicolumn{1}{c}{ Deskripsi } & Waktu \\
\hline 1 & 174 & Perintah_On_1 & 0 & Lampu Nyala & $2020-10-07$ 19:44:57 \\
2 & 175 & Perintah_On_2 & 0 & Lampu Jalan Nyala & $2020-10-07$ 19:46:00 \\
3 & 176 & Perintah_On_3 & 0 & Lampu Belakang Nyala & $2020-10-07$ 19:46:23 \\
4 & 177 & Perintah_On_4 & 0 & Mesin Pompa Nyala & $2020-10-07$ 19:46:32 \\
5 & 178 & Perintah_On_5 & 1 & Semua Relay Mati & 2020-10-07 19:46:54 \\
\hline
\end{tabular}




\section{E. Analisis Pengujian}

Setelah melakukan pengujian menyeluruh terhadap system smart home ini maka dapat disimpulkan bahwa:

1. Berdasarkan hasil pengujian, data yang disimpan pada server telah sesuai dengan data yang ditampilkan pada aplikasi android

2. History dapat dilihat oleh semua pengguna

3. Jika memiliki user akses telegram maka orang lain juga bisa mengaksesnya.

4. Jika system tidak menerima jaringan wifi maka system ini tidak akan bekerja.

\section{KESIMPULAN}

Beberapa kesimpulan yang dapat diambil dari penerapan sistem kendali otomatis smarthome pengendalian perangkat elektronik berbasis mikrocontroler dengan android adalah sebagai berikut: Sistem kendali otomatis smarthome pengendalian perangkat elektronik berbasis mikrocontroler dengan android dirancang menggunakan node mcu sebagai main unit atau otak dari sistem, dan beberapa modul pendukung seperti, relay $5 \mathrm{v} 4$ channel, dan diperintah dengan bahasa pemograman $\mathrm{c}++$ dengan aplikasi Arduino serta menggunkan android sebagai input perintah. Aplikasi remote smarphone menggunakan telegram, kontak aksesnya dibuat menggunakan botfather. Sistem kendali otomatis smarthome pengendalian perangkat elektronik berbasis mikrocontroler dengan android sangat efektif untuk membantu mengatasi pengguna dalam aktivitas sehari hari untuk menyalakan dan mematikan peralatan elektronik tertentu hanya dengan smartphone android yg ada pada genggaman.
Jika system dijalankan dan aplikasi sudah memberi tahu bahwa perangkat sudah hidup, tetapi nyatanya perangkat tidak hidup. Ini bisa jadi perangkat tersebut sudah rusak, maka diperlukan fitur monitoring untuk mengetahui keadaan perangkat tersebut.

\section{Daftar Pustaka}

[1] B. S. Andika, "Kontrol Lampu Rumah Berbasis Android," pp. 1-11, 2015.

[2] B. Anilkumar, N. Lakshmidevi, and P. Choudary, "Home Automation through Smart Phone using ESP8266 Wi-Fi Module by IOT," vol. 3, no. 4, pp. 17-21, 2017 .

[3] Kumar. Manu, Ekta, Agarwal. Shruti, Gaur dan Gupta, Yashdeep, "Internet Based Home Automation. International Journal of Research and Development Organization",in Journal of Electronics and Computer Science Vol. 2, Issue 8, Aug. 2015.

[4] Kusuma, Hendra, "Rancang Bangun Pengendalian Komunikasi Serial Modem Menggunakan Mikrokontroler Sebagai Alat Kontrol Jarak Lampu Penerangan," Skripsi, STMIK Atma Luhur, Pangkalpinang, 2017.

[5] Nasution, A. H., Indriani, S., Fadhilah, N., Arifin, C., \& Tamba, S. P., "Pengontrolan Lampu Jarak Jauh Dengan Nodemcu Menggunakan Blynk," Jurnal TEKINKOM, 93-98, 2019.

[6] T. Akhir, P. Studi, D. T. Informatika, J. T. Elektro, and P. N. Manado, "Aplikasi Android Menggunakan Media Bluetooth Berbasis Mikrokontroller," 2015.

[7] Qibtiyah, U. M., \& Rahayu, S. "Implementasi JSON Web Service pada Aplikasi Digital Library Politeknik Sukabumi," JTERA -Jurnal Teknologi Rekayasa, 9-16, 207. 